\title{
Can Patient Education with a Smartphone Application Improve the Quality of Bowel Preparation for Colonoscopy?
}

\author{
Yoo Jin Lee and Kyung Sik Park \\ Department of Internal Medicine, Keimyung University School of Medicine, Daegu, Korea
}

See "The Impact of Patient Education with a Smartphone Application on the Quality of Bowel Preparation for Screening Colonoscopy" by JeongHyeon Cho, SeungHee Lee, Jung A Shin, et al., 479-485.

Colonoscopy is an effective method for prevention of colorectal cancer and colorectal cancer-related mortality. ${ }^{1,2}$ For successful colonoscopy, adequate bowel preparation is essential. Inadequate bowel preparation may lower the cecal intubation rate, and increase the procedural time and number of missed lesions, which may require earlier repeated colonoscopy, ultimately increasing overall health-care expenditures. ${ }^{3}$ In spite of the importance given to bowel preparation, $18.0 \%$ $30.5 \%$ of patients still show suboptimal bowel preparation. ${ }^{4-6}$

The quality of bowel preparation can be influenced by many factors, including diet restriction, time and amount of taking purgatives, and patient factors, such as age, comorbidities, physical activity, and patient compliance. ${ }^{7}$ Among the factors associated with the quality of bowel preparation, patient compliance to purgative agent and dietary instructions has a potential to be improved with a careful and comprehensive effort. A previous study showed that noncompliance to bowel preparation instructions is a risk factor for inadequate preparation, with a considerable risk (odds ratio [OR] of 4.76 for inadequate preparation). ${ }^{8}$ Consensus guideline by the

Received: August 31, 2017 Accepted: September 19, 2017

Correspondence: Kyung Sik Park

Division of Gastroenterology and Hepatology, Department of Internal Medicine, Keimyung University School of Medicine, 56 Dalseong-ro, Jung-gu, Daegu 41931, Korea

Tel: +82-53-250-7088, Fax: +82-53-250-7442, E-mail: seenae99@dsmc.or.kr

(cc) This is an Open Access article distributed under the terms of the Creative Commons Attribution Non-Commercial License (http://creativecommons.org/ licenses/by-nc/3.0) which permits unrestricted non-commercial use, distribution, and reproduction in any medium, provided the original work is properly cited.
United States Multi-Society Task Force on bowel cleansing for colonoscopy stated that physicians should provide a patient educational program to achieve better bowel preparation. ${ }^{9}$ Thus, many educational tools have been suggested to improve patient compliance to instructions, including telephone calls, cartoon visual aids, and videos. ${ }^{10-12}$ Recently, a meta-analysis confirmed the effectiveness of enhanced education in improving the quality of bowel preparation (OR, 2.35; 95\% confidence interval [CI], 1.65-3.35; $p<0.001)$ and the patient's willingness to repeat the preparation (OR, 1.91; 95\% CI, 1.20-3.04; $p=0.006) .{ }^{13}$ However, the previously developed educational methods for bowel preparation are not universally utilized in reality. More-comprehensive interventions that are generally feasible, user friendly, and intensive are required.

In this issue of Clinical Endoscopy, Cho et al. studied the efficacy of educational intervention with a smartphone application (app) to improve bowel preparation quality. ${ }^{14}$ The educational app developed by the authors consisted of 4 sections: explanations of the colonoscopy procedure, dietary instructions, and instructions to prepare and drink the purgative agent. This study was conducted at a single center in Korea and included 142 patients indicated to undergo colonoscopy. Seventy-one patients were provided enhanced education via a smartphone app, and the rest were educated using traditional verbal and written instructions. Compared with the control group, the smartphone app group showed higher bowel preparation quality, as assessed with the Boston Bowel Preparation Scale $(7.70 \pm 1.1$ vs. $7.24 \pm 0.8, p=0.007)$. The app group showed higher satisfaction with the education delivery meth- 
od for colonoscopy preparation than the control group did. Working time, adenoma detection rate, and polyp detection rate did not significantly differ between the two groups.

This is an interesting and noteworthy study in the modern age, when the use of smartphones and apps is increasing rapidly. Smartphone usage in the South Korean population has been estimated to be approximately $86.4 \%{ }^{15}$ Coinciding with the popularity of smartphones, the use of smartphone apps in the medical field has been increasing recently. ${ }^{16,17}$ However, only few studies have evaluated the efficacy of smartphone apps in the field of patient education for bowel preparation. $^{6,18,19}$

The strengths of using an app for patient education include various educational contents, such as written instructions, visual aids, and instructional videos, and an alarm system. ${ }^{19}$ In addition, it is easily accessible and repeatable when patients want to review the contents. However, this intervention can be limited by the fact that it may be difficult to apply to elderly patients because most of them are not familiar with the use of a smartphone. Another problem is that costs are incurred when using mobile data during education via the smartphone app.

In this study, the efficacy of patient education with a smartphone app was evaluated in patients aged $\leq 50$ years. Whether it has the same effectiveness in the elderly remains unclear. The prevalence of adenoma increases sharply with age, thus, screening with colonoscopy usually starts at the age of 50 years in many countries. ${ }^{20}$ However, as the prevalence of advanced colorectal neoplasm is reported to be approximately $3.5 \%$ in subjects aged $<50$ years, ${ }^{21}$ attention to the necessity of screening colonoscopy in young adults is increasing. Thus, intervention is needed to increase the bowel preparation quality even in young patients.

In this study, unlike in other studies, the alarm alerting approaching colonoscopy was set 3 days before the procedure. After the colonoscopy appointment date was entered in the app, the alarm function started. For every meal, the app informed patients on what food items to eat. ${ }^{14}$ The alarm function can be the best advantage of education with a smartphone app. If the patient uses the alarm function well, the effectiveness of real-time education can be expected through this method.

In summary, the smartphone app could be a promising method of enhanced education for bowel preparation focused on the young population. However, as this method could be applied only to subjects who can easily access the Internet, the general utilization of a smartphone app as an enhanced education method for bowel preparation needs to be confirmed in a further study.
Conflicts of Interest

The authors have no financial conflicts of interest.

\section{REFERENCES}

1. Winawer SJ, Zauber AG, Gerdes H, et al. Risk of colorectal cancer in the families of patients with adenomatous polyps. National polyp study workgroup. N Engl J Med 1996;334:82-87.

2. Imperiale TF, Glowinski EA, Lin-Cooper C, Larkin GN, Rogge JD, Ransohoff DF. Five-year risk of colorectal neoplasia after negative screening colonoscopy. N Engl J Med 2008;359:1218-1224.

3. Chorev N, Chadad B, Segal N, et al. Preparation for colonoscopy in hospitalized patients. Dig Dis Sci 2007;52:835-839.

4. Ness RM, Manam R, Hoen H, Chalasani N. Predictors of inadequate bowel preparation for colonoscopy. Am J Gastroenterol 2001;96:17971802.

5. Sherer EA, Imler TD, Imperiale TF. The effect of colonoscopy preparation quality on adenoma detection rates. Gastrointest Endosc 2012;75:545-553.

6. Kang X, Zhao L, Leung F, et al. Delivery of instructions via mobile social media app increases quality of bowel preparation. Clin Gastroenterol Hepatol 2016;14:429-435.e3.

7. Froehlich F, Wietlisbach V, Gonvers JJ, Burnand B, Vader JP. Impact of colonic cleansing on quality and diagnostic yield of colonoscopy: the European panel of appropriateness of gastrointestinal endoscopy European multicenter study. Gastrointest Endosc 2005;61:378-384.

8. Chan WK, Saravanan A, Manikam J, Goh KL, Mahadeva S. Appointment waiting times and education level influence the quality of bowel preparation in adult patients undergoing colonoscopy. BMC Gastroenterol 2011;11:86.

9. Johnson DA, Barkun AN, Cohen LB, et al. Optimizing adequacy of bowel cleansing for colonoscopy: recommendations from the US multi-society task force on colorectal cancer. Gastroenterology 2014;147:903-924.

10. Liu X, Luo H, Zhang L, et al. Telephone-based re-education on the day before colonoscopy improves the quality of bowel preparation and the polyp detection rate: a prospective, colonoscopist-blinded, randomised, controlled study. Gut 2014;63:125-130.

11. Tae JW, Lee JC, Hong SJ, et al. Impact of patient education with cartoon visual aids on the quality of bowel preparation for colonoscopy. Gastrointest Endosc 2012;76:804-811.

12. Park JS, Kim MS, Kim H, et al. A randomized controlled trial of an educational video to improve quality of bowel preparation for colonoscopy. BMC Gastroenterol 2016;16:64.

13. Guo X, Yang Z, Zhao L, et al. Enhanced instructions improve the quality of bowel preparation for colonoscopy: a meta-analysis of randomized controlled trials. Gastrointest Endosc 2017;85:90-97.e6.

14. Cho J, Lee S, Shin JA, Kim JH, Lee HS. The impact of patient education with a smartphone application on the quality of bowel preparation for screening colonoscopy. Clin Endosc 2017;50:479-485.

15. Korea Internet \& Security Agency. 2015 Survey on the mobile internet usage executive summary [Internet]. Naju: Korea Internet \& Security Agency; c2016 [updated 2016 Feb 22; cited 2017 Aug 31]. Available from: http://www.kisa.or.kr/eng/usefulreport/surveyReport_View. jsp? PPage $=1 \& p \_N o=262 \& b \_N o=262 \& d \_N o=71 \& S T=\& S V=$.

16. Kim J, Lim S, Min YH, et al. Depression screening using daily mental-health ratings from a smartphone application for breast cancer patients. J Med Internet Res 2016;18:e216.

17. Park JH, Kim YK, Kim B, et al. Diagnostic performance of smartphone reading of the coronary $\mathrm{CT}$ angiography in patients with acute chest pain at ED. Am J Emerg Med 2016;34:1794-1798.

18. Sharara AI, Chalhoub JM, Beydoun M, et al. A customized mobile application in colonoscopy preparation: a randomized controlled trial. 


\section{C clinical endoscopy}

Clin Transl Gastroenterol 2017;8:e211.

19. Lorenzo-Zúñiga V, Moreno de Vega V, Marín I, Barberá M, Boix J. Improving the quality of colonoscopy bowel preparation using a smart phone application: a randomized trial. Dig Endosc 2015;27:590-595.

20. Kim JY, Jung YS, Park JH, et al. Different risk factors for advanced col- orectal neoplasm in young adults. World J Gastroenterol 2016;22:36113620.

21. Kim JK, Choi YS, Suh JP, Lee IT, Youk EG, Lee DS. Results of screening colonoscopy in asymptomatic average-risk Koreans at a community-based secondary hospital. Korean J Gastrointest Endosc 2010;41:266-272. 